Рецензии: Аостоевский на сцене

УДК $801.731+82.2+821.161 .1+821.111$

ББК $83+8533+83.3(2)+83.3(4)$

DOI 10.22455/2619-0311-2020-2-211-221

Вера Сердечная

\author{
Ставрогин совращает Тэль: \\ «Книга Серафима» Александра Белоусова \\ в Электротеатре Станиславский
}

Vera Serdechnia

\title{
Stavrogin Seduces Thel: "The Book of Seraphim" by Alexander Belousov at the Stanislavsky Electrotheatre
}

Об авторе: Вера Владимировна Сердечная, кандидат филологических наук, научный редактор, издательский дом «Аналитика Родис» (Краснодар).

E-mail: rintra@yandex.ru

Для цитирования: Сердечная В.В. Ставрогин совращает Тэль: «Книга Серафима» Александра Белоусова в Электротеатре Станиславский // Достоевский и мировая культура. Филологический журнал. 2020. № 2(10). С. 211-221.

DOI 10.22455/2619-0311-2020-2-211-221

About the author: Vera V. Serdechnia, Candidate of Philological Sciences, Academic Editor, Publishing House “Analitika Rodis” (Krasnodar).

E-mail: rintra@yandex.ru

For citation: Serdechnia V.V. Stavrogin Seduces Thel: "The Book of Seraphim” by Alexander Belousov at the Stanislavsky Electrotheatre. Dostoevsky and World Culture. Philological journal, 2020. No. 2(10), pp. 211-221.

DOI 10.22455/2619-0311-2020-2-211-221 


\section{ЭЛЕКТРОТЕАТР МАЛАЯ СЦЕНА}
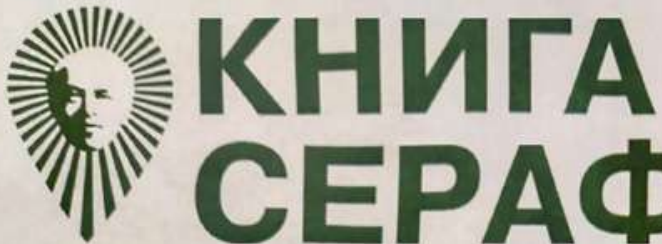

По поэме Уйьsмa Бnейка

- Kunra Tomb" и фрагменту

романа Федора Достоенскоro =Бесы:

Режиссер и композитор

Aneксанцр Белоусов
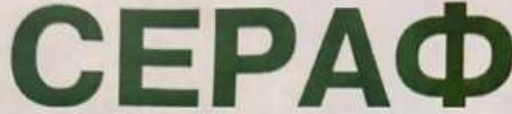

ИIM

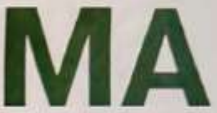

$\rightarrow 2$

IV .

The eternal jates terrific porter lified the northern bar:

Thel enterid in \& saw the secrets of the liend untrown:

Sigh saw the concibes of the dead. \& where the forrous roots Of every heart an earth iatixes derp its erstels busts.

I land of sorrows \& of thus where never somle was saven.

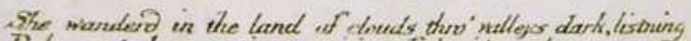

Dolours \& lamertartions: waitem att bestide a dest zrave

She stoad in silence. listrunt to the voucs of the pround,

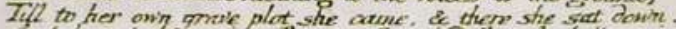

Hud heand this vocice of 'sorrow breathed frome the hollow' pit.

Why canmut the Ear be clased to its orin drstructian."

Whe oflusming Eve to the poison of a smile!

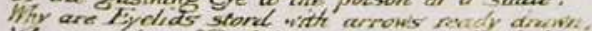

Whan a thousand trighting mers is umbuste lie:

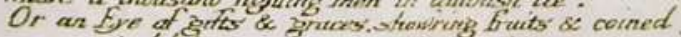

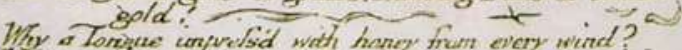

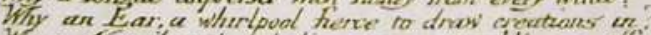

Wha a Mastril wide invialin: ierror inmbling as atfrich

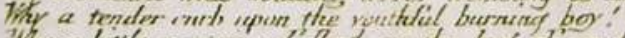

Why a latte curtarn of thesh an the bed af cur desire.

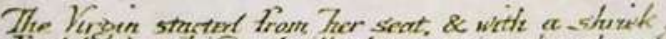

Fled back unthenderd all she crune unto the males of

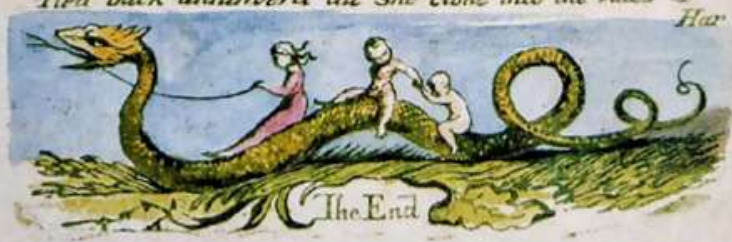




\section{КНИГА СЕРАФИМА}

По поэме Уильяма Блейка "Книга Тэль" и Фрагменту романа Фёдора Достоевского “Бесы”

Режиссер и композитор:

Александр Белоусов

Музыкальный руководитель:

Арина Зверева

Ассистент музыкального руководителя:

Дмитрий Матвиенко

Художник: Ася Мухина

Хореограф: Александра Конникова

Художник по свету: Алексей Наумов

Звукорежиссер: Михаил Иванов

Саунд-дизайнер: Oлег Макаров

Live electronics: Леонид Именных

Консультант по электронике:

Константин Смирнов

\author{
В ролях: \\ Тэль Поющая - Ольга Россини, солистка \\ ансамбля N'Gaged \\ Тэль Танцующая - Екатерина Андреева \\ Тихон - Дмитрий Матвиенко, солист \\ ансамбля N'Gaged \\ Ставрогин - Сергей Малинин, солист \\ ансамбля N'Gaged \\ Нарратор - Владимир Красов \\ Лилия - Светлана Мамрешева \\ облако - Алёна Парфёнова \\ Дочери Серафима - Илона Буль, \\ Елена Быркина, Алина Горина, Алёна Кахута, \\ Татьяна Перевалова
}

В записи фонограммы оркестра участвовали: Светлана Безотосная, Михаил Звонников, Анна Звонникова, Филипп Крючков, Денис Кузнецов, Анастасия Кускашёва, Мария Лукьяшина Дирижер: Дмитрий Матвиенко

Помощник режиссера: Евгения Фурман

Линейный продюсер: Варвара Пушкарская

В oneре Александра Белоусова смонтированы два текста: поэма Уильяма Блейка «Книга Тэль» (1789) и глава «У Тихона" из романа Фёдора Достоевского «Бесы». Героиня Блейка в поиске причины своей тоски обращается к Лилии долин, потом к Облаку и Червю и наконец попадает в лоно Земли, где обнаруживает источник страдания человека. Герой Достоевского Николай Ставрогин приходит к архиерею Тихону и предоставляет письменное свидетельство своих грехов.

В обоих случаях речь идет о Желании. Если в поэме Блейка Желание только обнаруживается (за столетие до Фрейда) как сила, толкающая и влекущая человека по пути познания, то у Достоевского Ставрогин говорит: «я всегда господин себе, когда захочу" ,

Название «Книга Серафима" отсылает нас к имени отсутствующего рассказчика - того Фантастического ветхозаветного существа, чьими глазами зритель видит и слышит историю и чье изображение помещает Блейк на последней странице собственноручного издания своей поэмы.

В спектакле используется перевод Константина Бальмонта поэмы Уильяма Блейка «The Воok of Thel" на русский язык («Книга Тэль», 1921) и перевод Вирджинии Вулф (и Сэмюэля Котелянского) фрагмента романа Достоевского “Бесы» на английский язык («Stavrogin's Confession», 1922). 
В последнее время мне довелось увидеть немало интересных постановок по Достоевскому в разных концах страны. Например, «Братья Карамазовы» Максима Соколова в Архангельском молодежном театре - сложный микс из текста Достоевского, играемый в тесной комнате, со смелыми режиссерскими решениями и самоотверженной актерской работой. Или «Бесы» Григория Лифанова в Севастопольском театре драмы им. Луначарского - масштабное, наполненное молодой энергией артистов зрелище о конфликте традиционной русской культуры и современных разрушительных веяний. А также «Идиот» Андрея Прикотенко в новосибирском театре «Старый дом» - перенос действия в современность, с Мышкиным-хипстером и яркими сценическими метафорами.

Режиссер и композитор Александр Белоусов принимает неочевидное, на первый взгляд, решение по сочетанию двух текстов разных эпох и культур. В спектакле Электротеатра Станиславский он объединяет в мультижанровой природе оперы «Бесов» Достоевского (точнее, признание Ставрогина) и поэму английского романтика Уильяма Блейка «Книга Тэль» (The Book of Thel). Достоевский Блейка не читал, однако у них есть история сопоставления: так, Андре Жид говорил об их обращении к одним и тем же неразрешимым вопросам, а Чеслав Милош видел в них писателей, с особенной силой осознавших трагедию крушения христианской цивилизации.

Александр Белоусов, ученик знаменитого реформатора театра Анатолия Васильева и мастерской МИР Бориса Юхананова, до «Книги Серафима» поставил в Электротеатре Станиславский оперу «Маниозис 1+2», стал композитором ряда спектаклей и автором серии звуковых перформансов. Писать об опере для филолога очень непросто, однако опора на текстуальные составляющие и на знания о современном театре служат проводником в этом занятии а театральный текст «Книги Серафима», конечно, взывает к истолкованию.

В спектакле Электротеатра Станиславский тексты Достоевского и Блейка объединены как посвященные одной 
теме: желания. Наивная дочь Серафима, Тэль, у Блейка стремится познать реальную жизнь, - чтобы в страхе бежать от ее угроз. Ставрогин у Достоевского, ведомый желанием, также выходит за границы представимого и морально состоятельного. Таким образом, ключевой точкой для сопоставления двух текстов становится тема желания, а ключевым событием - преодоление точки невозврата.

Спектакль начинается с диалога Ставрогина (Сергей Малинин) и Тихона (Дмитрий Матвиенко). Диалог этот происходит еще до входа в зал, на лестнице; «кающийся», по традиционной пространственной иерархии, находится снизу. Композитор разбивает текст Достоевского на такты, и этот речитатив ритмичен и красив, хотя и атонален, наполнен неожиданными паузами между тактами, порой посреди слова или фразы. Текст звучит по-русски; однако на экран выводятся титры на обоих языках. Вскоре включается и текст Блейка, вступление к поэме, который поется ангелическим сопрано Ольги Россини.

Текст небольшой поэмы Блейка взят полностью, а из Достоевского взят лишь фрагмент романа (глава «У Тихона»), причем выборочно: таким образом, режиссер сопоставляет конфликт «Книги Тэль» с тем конфликтом, который составляет тайную муку героя Достоевского. Преломляя поэму Блейка через роман Достоевского, Белоусов усложняет ее проблематику; вместе с тем диалогизм русского реалиста в полной мере свойствен и раннему английскому романтику, что можно увидеть из драматической природы «Книги Тэль».

Структура спектакля поначалу строится последовательно: фрагмент из Блейка, фрагмент из Достоевского; однако затем эта последовательность размывается. Спектакль становится все сложнее в игре двух языков и двух текстов, вплоть до того что звучит несколько звуковых потоков: одновременно Блейк и Достоевский в оригинале и переводе. Интересно отметить, что для перевода «Книги Тэль» Белоусов выбирает перевод Бальмонта - это верлибр, очевидно, более отвечающий структуре текста Достоевского. Отрывок «Бесов» дан в переводе Вирджинии Вулф 
и Сэмюэля Котелянского. Можно отметить и то, что для режиссера важен диалог с переводным текстом серьезных писателей своего времени (Бальмонт и Вулф).

Из-за равновесного использования двух языков принципиальным аспектом спектакля становится письменный текст: он все время представлен на мониторе, будь то в зале или на лестнице, в прологе. В многоголосье текстов и языков, в синкретической природе сообщения (музыкального, визуального, пластического, текстового) театр такого типа отвечает современному состоянию познающего сознания, которое сталкивается и сживается с усложнением и убыстрением информационного потока. В многомерной структуре театрального текста есть место и многоуровневости (сцены), и игре с ритмами и словами, и крупным планам видео, на котором и блейковская Тэль может, забывшись, кривляться, словно перед вебкамерой.

Режиссер Белоусов и художник Ася Мухина осмысливают мир Блейка-Достоевского как мир детей, своего рода песочницу цивилизации, которая только начинает свой инициатический путь. На сцене Тэль, ищущая опыта, выделяется из группы Дочерей Серафима - девочек-подростков в белых матросках и с букварями советского периода. Славное, сладкое ностальгическое прошлое без точных хронологических примет. Тэль здесь «раздваивается» на Тэль поющую (Ольга Россини) и Тэль Танцующую (Екатерина Андреева): одна поет текст, другая проживает-протанцовывает перипетии сюжета.

Именно Тэль станет в рамках этой постановки Матрешей, жертвой Ставрогина.

Сценография спектакля - это детская игровая площадка; за оградкой расположены лестница с турником, качели, даже расстелен в углу ковер, на который рассаживаются «девочки» с букварями. Вот только покрытие на этой площадке - металлическое, и по нему отбивается жесткий и четкий ритм; Дочери Серафима отбивают его то лопатками для песочницы, а то и электрическими зубными щетками.

Поиск Тэль у Блейка - это поиск опыта: она спрашивает о мире у Лилии, Облака, Червя и Земли. Одним из 
традиционных толкований поэмы является мысль о том, что Тэль (как и другие дочери Серафима) - нерожденная душа, которая заглядывает в мир порождения. В то время как традиционной основой сюжетной структуры становится событие, пересечение определенной границы заранее известных действий, в «Книге Тэль» эта закономерность нарушается: испуганная противоречиями материально-телесного мира, юная Тэль бежит в свои идиллические долины обратно, не отваживаясь на пересечение границ обыденного.

Однако Тэль, внезапно, не чужда Ставрогину в смысле наличия желания, осознанного стремления проверить возможность нарушения границ. Это стремление выдает в обоих этих персонажах потенциал героя - то есть того, кто нарушает запрет, выходит за пределы, а затем и (потенциально) служит к исправлению мира.

Спектакль подвергает вопросам и текст романтика, и текст реалиста. В роли благополучного вещателя истин здесь выступает поначалу Нарратор (Владимир Красов). Однако его дивно красивые, мелодичные реплики по английскому тексту Блейка к середине замолкают; он в какой-то момент обращается чиновником, над которым смеется Ставрогин, а потом и вовсе замолкает, тяжко осев на металлический пол площадки.

В спектакле «сюжетный» Ставрогин, как и Дочери Сeрафима, появляется как мальчишка-переросток, в синем бархатном костюмчике и бескозырке: то ли юная, то ли молодящаяся культура, беззаботно пытающаяся проверить, работает ли моральный запрет. Их танец с Тэль, параллельный тексту о Матреше, - не столько насилие, сколько соблазн; в контексте визуального решения это взаимное обольщение двух подростков, грешное лишь настолько, насколько грешно желание само по себе.

После танца-соблазна Тэль ложится на ковер, подняв ноги на стену, и долго лежит так. Она меняется: тяжелеет походка в черных туфлях, слетает с головы бант. Диалог с Землей Тэль Танцующая проводит сидя в цинковой ванне, засыпанная по пояс почвой. И когда она встает, зритель видит, что она беременна. 
Режиссер идет в какой-то мере и против Блейка, и против Достоевского, переосмысливая оба произведения. Тэль здесь не остается в невинности, а невинная жертва Ставрогина уже не является жертвой в прямом смысле слова. В самом начале спектакля почти на головы зрителей падает из лестничного просвета белое платье - в позе повешенного, но без повешенного. И Тэль, соблазненная (или соблазнившая), несет плод: любовь на детской площадке оказалась не бесплодной. И как бы не вытягивала Тэль матрешинский кулачок вперед, как бы мрачно не звучал ритм, отстукиваемый по железному полу сценической площадки, - режиссер предлагает новое осмысление судьбы цивилизации, где невинность не боится опыта, и где страсть уже не наказуема, кажется, вечными муками совести.

Лейтмотивом спектакля становится потрясающая блейковскую Тэль мысль о том, что каждый живет не ради себя, что мир исполнен самопожертвования. Эта идея глубоко созвучна и творчеству Достоевского. 


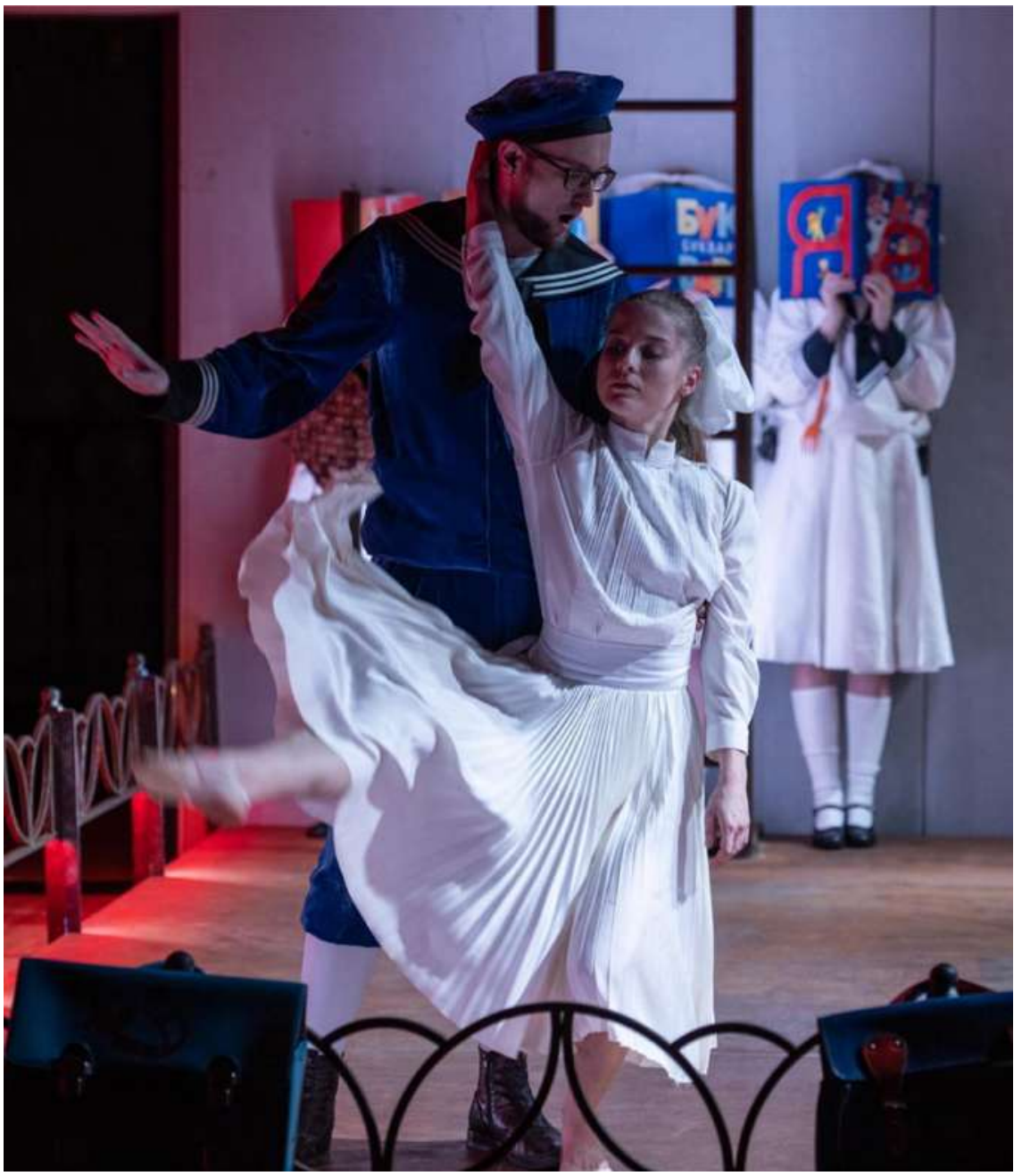

С. Малинин (Ставрогин) и Е. Андреева (Тэль Танцующая).

Фото О. Орловой. 


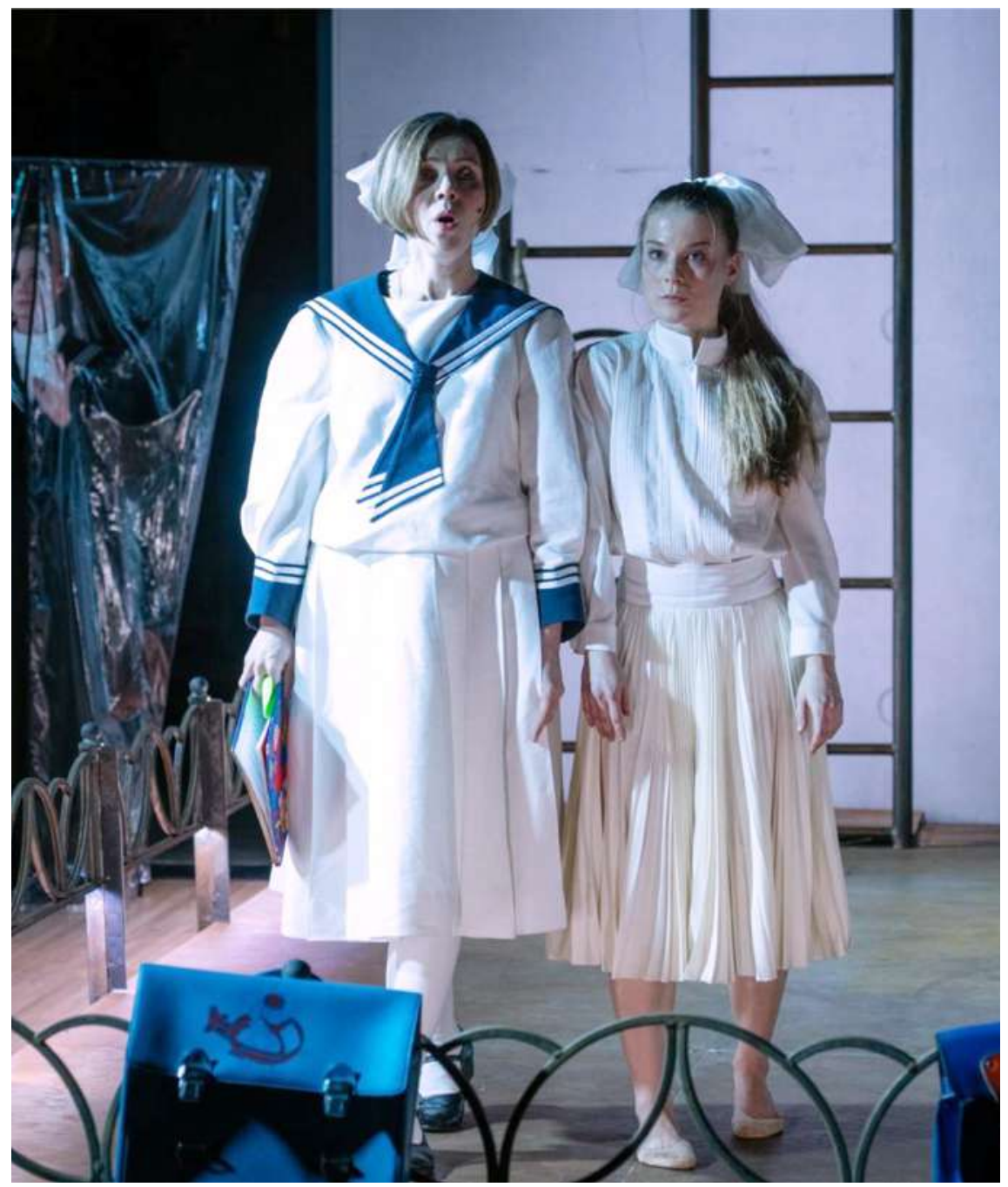

О. Россини (Тэль Поющая) и Е. Андреева (Тэль Танцующая). Фото О. Орловой. 


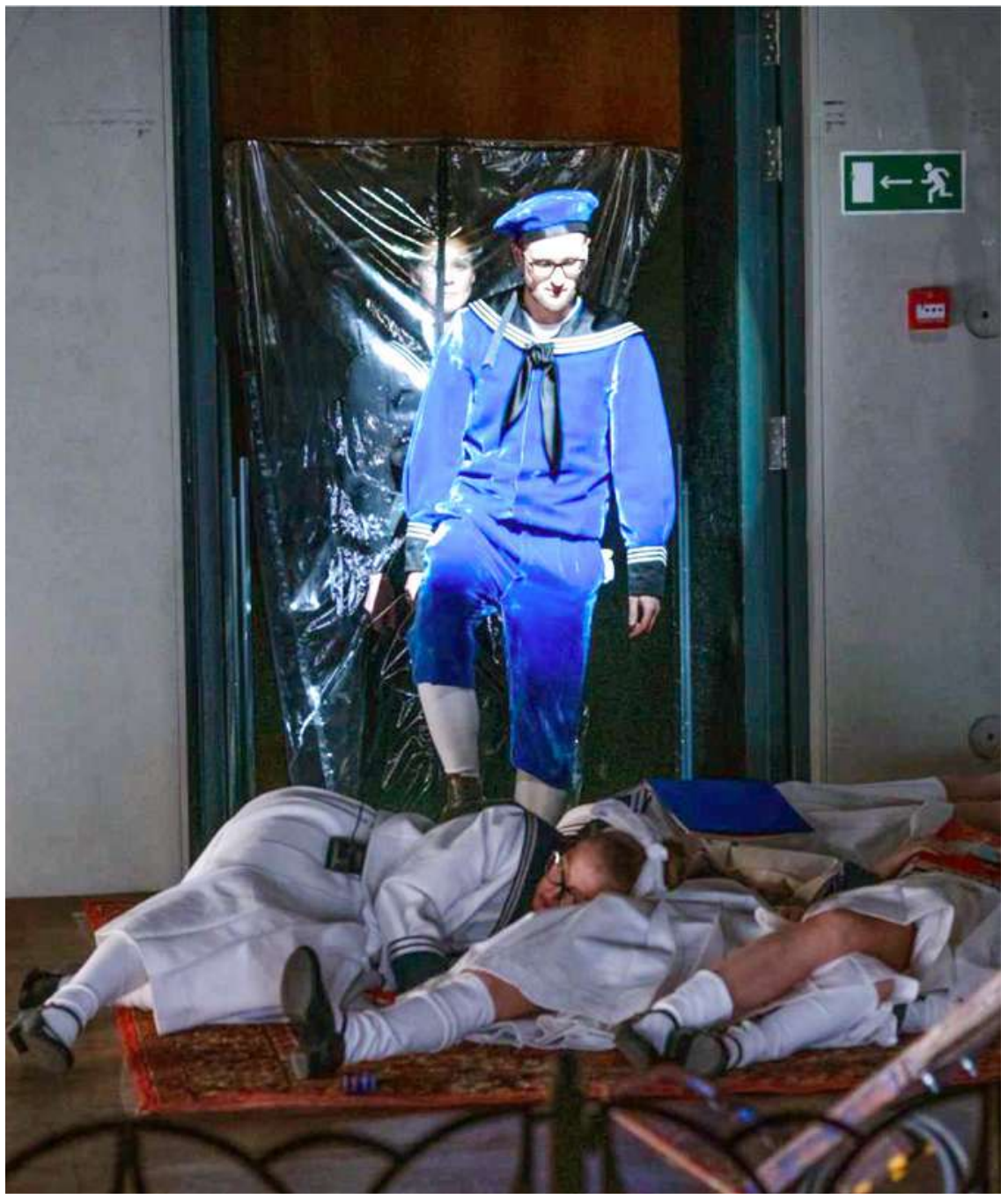

С. Малинин (Ставрогин) и Дочери Серафима. Фото О. Орловой. 